\title{
APPLICATION OF THE REAL OPTIONS METHODOLOGY TO VALUE A CEMENT FIRM'S ACQUISITION
}

\author{
Roberto J. Santillán Salgado* \\ Escuela de Graduados en Administración y Dirección de Empresas \\ Tecnológico de Monterrey, Campus Monterrey
}

(Received 13 September 2004, accepted 17 November 2004)

\begin{abstract}
Discounted Cash Flow (DCF) analysis provides a conventional valuation platform for accuisition targets. Real Options Analysis (ROA) improves the quality of an acquisition's valuation through an objective determination of the worth of future possible managerial decisions (flexibility) that would be called for under different environmental scenarios.

ROA is exemplified with a traditional $D C F$ valuation of a target company in the cement industry to which the value of the ROA determined most important synergies is added. Finally both results are contrasted. The exercise concludes that by using ROA, acquiring firms may have a better informed negotiation position vis à vis the selling party.
\end{abstract}

\section{Resumen}

El Modelo de Flujo de Efectivo Descontado (FED) proporciona una plataforma convencional para la valuación de una adquisición empresarial. El Análisis de Opciones Reales (AOR) mejora la calidad de la valuación de la adquisición con base en la determinación objetiva del valor de las decisiones gerenciales (flexibilidad) que podrían ejecutarse en distintos escenarios.

Se ejemplifica el AOR con la valuación tradicional FED de una empresa candidata a ser adquirida, a la cual se agrega el valor determinado mediante AOR de las principales sinergias. El ejercicio concluye que mediante la utilización de AOR, las empresas adquirentes pueden lograr una posición negociadora mejor informada vis à vis la parte vendedora.

JEL classification: $C 63, G 12, G 34$

Keywords: Computational techniques, Asset pricing, Acquisitions

* Escuela de Graduados en Administración y Dirección de Empresas, Tecnológico de Monterrey, Campus Monterrey. Av. Fundadores y Rufino Tamayo, Valle Oriente, Garza García, Nuevo León, México. C.P. 66269. E-mail: roberto.santillan@itesm.mx

The author is very grateful to anonymous referees for their comments and wishes recognize to recognize the research assistance of Beatriz Mota, Eduardo Drucker and José Luis Pureco. Research facilities and financial support from ESC-Lille, France, is also very gratefully acknowledged. 


\section{Introduction}

Acquisitions represent a fundamental building block for the strategy of numerous companies that base their growth and penetration of new markets on takeovers of already existing firms. A characteristic that has been reported over and again as a common trait to the vast majority of public companies' acquisitions is that the price paid for the stock of the target firm is significantly higher than the ongoing stock market price.

Evidently, "sweetening" the deal is unavoidable when the target company's stock is publicly held, to entice current stockholders to take advantage of the "opportunity". However, evidence on the existence of an "acquisition premium" paid by the acquiring candidate has raised frequent criticisms against the "excessive" prices paid. Frequently, also the price of the acquirer company's shares decreases after the transaction announcement.

Acquirers usually justify paying a premium above the ongoing market price for the stock of their target arguing that the value "as is" omits considering potential synergies that will become effective once the takeover of control allows a number of operating and strategic adjustments. That explanation is basically equivalent to saying that "the market does not correctly incorporate the value of growth opportunities", i.e. markets are not "sufficiently" efficient. That argument could also explain why the acquiring company's stock price drops, given only insiders, and not the general public, understand and correctly value the growth opportunities embedded in the target.

A more objective and straightforward interpretation of the negative reaction of the acquiring company's stock price is that even when an acquisition may indeed bring improvements and benefits through a better utilization of assets, enhanced productivity or the acquisition of new technologies, the price to be paid for the acquisition happens to be so high that it represents a net transfer of wealth from the acquirer's shareholders to the target's shareholders.

Eccles, Lanes and Wilson (1999) explain the post-acquisition deceiving performance of many acquirers' stock in terms of the "irrational exuberance about the strategic importance of the deal, enthusiasm built up during the excitement of negotiations, and weak integration skills, to name a few".

Based on a research project on mergers and acquisitions (M\&A) addressed at understanding how should managers think about "what to pay" for an acquisition, the same authors report the answers of 75 senior executives from 40 companies. Among other significant findings, the survey found that "there's a systematic way for senior managers to think about pricing acquisitions". However, emotional attachment to a deal may distort the objectivity required in such large price-tag transactions.

It follows that corporations interested in participating in the M\&A market must have a set of organizational principles and rules that enforce analytical rigor to help senior executives "guide their companies toward the right acquisitions at the right price".

The aim to attain exactness in the valuation of acquisition targets is consistent with the objective of maximizing shareholders' value. Paying too much for an acquisition means diluting the current shareholders' wealth and transferring 
it to the target's owners; however, paying too little may put the transaction at risk and represent a major flaw in the execution of the corporation's strategy.

It should be emphasized that the "right" price for an acquisition is not the same for any potential buyer. On the contrary, it is different for different potential acquirers because in addition to the value "as is", the intrinsic value of the target changes as a function of the possible synergies that, in turn, depend on the nature of the buyer. While the same target may represent a perfect fit for one potential buyer, it may at the same time represent a "not so good" complement for another candidate. In the first case, the candidate acquirer would be willing to pay a greater premium while in the second it may try to succeed in the acquisition, but not really push to the limit of its forces to keep it. Thus, prices eventually paid for an acquisition may reflect the "goodness of fit" of an acquisition with respect to the acquirer. Eccles, Lanes and Wilson (1999) report two subsets of 10 acquisitions each, classified according to the size of the premium. While after one year the low premium deals (less than 20\%) recorded negative market returns (from $-9 \%$ to - 59\%), the high premium subset (more than $34 \%$ up to as much as $115 \%$ ) obtained positive market returns (from $4 \%$ to $49 \%$ ). These results support the argument that when an acquiring firm sees an interesting compatibility potential it pays a high premium. Once the acquisition takes place and the potential synergies become a reality, the market recognizes the new value created and bids up the price of the stock.

By contrast, when prices paid for an acquisition are barely above the ongoing market price it is likely the case that the acquiring firm doesn't find a clear synergy potential and for that reason is not willing to pay a higher premium. Lack of clarity in this important regard might even result in a flawed decision that instead of creating additional value destroys it.

\section{Traditional Valuation}

The intrinsic value of a target firm, also known as the value "as is", assumes it continues under the control of the current board of directors. It is measured by means of a Discounted Cash Flow model based on future expected cash flow projections that incorporate any medium and long term foreseeable revenue growth as well as publicly known planned improvements (modernization, restructuring, etc.).

Besides the intrinsic value, the market may include a premium on the price to reflect the likelihood that an offer for the company will be made, and for that reason the observed market price can deviate from the estimated intrinsic value. This latter component is rather difficult to measure since it is significantly influenced by expectations and continuously arriving information.

From the acquirer's perspective, the tentative price must be sufficiently above the intrinsic value plus the "likelihood of acquisition" premium to entice the current owners of the target to sell their shares. However, an acquirer needs to make sure that the price paid leaves enough room for a full recovery of the investment and to generate an appropriate profit margin, i.e., that the transaction represents a Positive Net Present Value that adds to its worth. The difference between the intrinsic value of the target and its "expected value" under new management must therefore be explained by potential synergies. 
Figure 1. Intrinsic value of target vs. Full value for acquirer

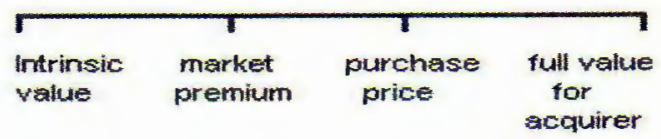

The potential sources of synergy value in an acquisition are numerous; their relative importance from one case to another depends on factors such as the type of industry, the technology, current state-of-the-art and rhythm of change, the intensity of competition, the particular characteristics of the acquiring and the target companies, etc.

Operational cost savings are the most common type of synergies and are usually relatively easy to estimate, since they can be directly associated with specific technical processes, organizational procedures and/or economies of scale. They are frequently obtained as a result of the elimination of redundant areas, unproductive employments or the replacement of obsolete assets. Savings are frequently significant in those cases of acquisitions within the same industry and the same geographical region.

Efficiency improvements can result from combining business entities of uneven managerial sophistication. By acquiring a relatively less efficient target, the buyer can increase value improving the efficiency of the target. This relationship can happen the other way around, i.e., a relatively inefficient company may be interested in merging with or acquiring a target that enjoys a better profile (administrative processes, information technology, market knowledge) with the intention of absorbing the "best practices" of the target.

Firms that count with significant flexibility in their marketing, manufacturing, and financing functional areas may achieve additional benefits from strategic acquisitions when these represent diversification opportunities. In that sense, an acquisition program that focuses on strategic diversification will not only decrease the variance of the firm's expected cash flows, but it may significantly increase firm value by enhancing the value of the firm's flexibility options (Kulatilaka and Trigerorgis, 1994).

Value is also created by achieving a better utilization of the existing asset base, including economies of scale, sale or write-off of inefficient plants or redundant processes, etc. According to Copeland and Antikarov (2001), economies of scale arise because of indivisibilities, such as people, equipments and overhead that result in lower costs if spread over a large number of units of output. Other potential areas of synergy are, for example, the integration of separate areas of research and development (laboratories, test fields, staff) to create a critical mass capable of initiating a process of clear differentiation and competitive advantages development.

Sometimes acquirers target firms by their location due to the relative abundance of essential factors to sustain a competitive advantage. This is particularly true in the case of firms pertaining to the New Economy, like biotechnology, software or dot-com companies, due to the high geographical concentration of expert talent and supporting services providers. 
Eventually, combining two or more companies raises important questions for top management when it becomes necessary to decide how to coordinate the good parts of the organizations and get rid of redundant or non-performing areas. The human factor can easily become a serious issue, in particular when potential layoffs organize to react defensively and boycott the process in an attempt to avoid their fate.

Often, areas identified as potential synergies result in non adequate fits due to poor before-the-fact analysis. When a fast and untidy analysis "not to loose the opportunity" is made as support of a transaction, areas of opportunity in certain dimensions of both acquirers and targets may seem to benefit through a merger or acquisition process. However when looked at in more detail one does not really reinforce the other because the underlying causes of relative disadvantage may be very different from the strengths that the transaction will incorporate. For example, a company whose apparent area of opportunity lies in an improvement of its marketing skills because it has not been able to defend its market share in recent times may not benefit with the acquisition of another entity with strong marketing skills because the true underlying reason of unsatisfactory performance may be a deficient customer service or poor quality control.

Another potential source of complementation and synergy is vertical integration. By combining firms at different levels of the value added chain a former market supplier-customer relationship may become smoother and better coordinated process that results in reduced costs, thus reverting into higher profitability. Sometimes that integration may require a minimum degree of commitment of resources and may be a short-term effort, while some other times finding the right mix may become significantly more complex.

For some firms the benefits of acquiring a target may not only come from the operations synergies side, but also by interesting diversification results. This is particularly true for firms that participate in emerging countries whose markets offer attractive growth potential, but are frequently subject to inestability.

While diversification gains are intuitively clear, measurement for adequate evaluation of the decision may pose a challenging exercise, mainly because it is not a historical diversification measurement, which is not at all difficult from a statistical point of view, but an ex-ante guess.

Even when diversification may be achieved through internal growth, acquisitions bring along elements that cannot be developed overnight, like brand recognition, reputation, research and development advances, human capital, etc.

A very important source of potential synergies that must not be overlooked in the valuation of an acquisition is the financial synergy resulting from lower costs of internal financing. When firms with large internal cash flows and small investment opportunities have excess cash flows and use them to acquire firms with a need for additional financing, there is a high possibility that lower costs of internal financing will "create" value for shareholders (Copeland and Antikarov, 2001). In support of that argumentation we have the empirical results of Nielsen and Melicher (1973) who report that the rate of premium paid to the acquired firm owners as an indirect valuation of potential gains from the transaction was 
significantly greater when the acquirer had more generous cash flow rates than the target.

Larger firms may face better opportunities to obtain credit from bankers and to place bond issues in the market due to the perception of greater solidity and guarantee. Since there is always a fixed component in those transactions, the integrated average cost of debt may diminish allowing for greater availability of financial resources to support operations and new strategic ventures.

While the classical argument of Modigliani and Miller would suggest there is no benefit potential in an acquisition from the perspective of increased debt capacity, the existence of an interest tax deduction generates greater cash flows to stakeholders (bondholders and shareholders), thus increasing the firm's value.

\section{The Real Options Approach}

Some of the gains obtained through an acquisition can be estimated with a good precision level and almost no uncertainty (hard synergies), but many others contain high levels of uncertainty and are frequently contingent on the existence of particular conditions to justify further investments that will allow the acquiring firm to profit with them (soft synergies).

It used to be that less certain potential gains were estimated subjectively by experienced managers whose trained eyes could penetrate beyond the most immediately realizable benefits. However, when the precision of the target firm's valuation is important to determine if wealth is being created or destroyed or if the bidding process should go any further at some point during a takeover attempt, a more refined and flexible methodology can be applied: the Real Options Approach.

Several arguments support the decision to reformulate the valuation analysis of an acquisition with that new approach. First, DCF fails to capture the value of managerial flexibility as well as that of future strategic decisions such as the option to expand, delay, abandon a project, or switch technologies, energy sources, etc. Second, for a firm with a large ingredient of growth opportunities, the potential cash flow is, in general, highly volatile. This implies a difficult and usually imprecise calculation of the risk premium used to determine the appropriate discount rate. Third, growth opportunities exhibit a significant nonlinearity, an obvious difficulty for traditional cash flow methods. Finally, DCF analysis is static in nature and assumes growth opportunities either are not totally reversible or are "now or never" opportunities (Ottoo, 2000).

Kulatilaka (1993) has proposed a real option approach for capital investment projects that include flexible manufacturing. Kulatilaka and Perotti (1998) deveioped a simple valuation model that incorporates the real options concept for a strategic acquisition simulated example. Contingent claims models have been shown to resolve many of the shortcomings of DCF methods in evaluating growth opportunities (Ottoo, 2000). These models utilize the implicit assumption of flexibility and growth opportunities as "real" options. Growth opportunities, as well as the opportunity for flexible decision making, account for a significant portion of the asset value of many firms. There is an obvious need to introduce new, more flexible valuation techniques that incorporate the value of future alternative paths of strategy. 
Real options are valuable because they better model managers' flexibility to take advantage of opportunities in order to increase profits or to decrease losses (Lander and Pinches, 1998). According to Baldwin (1987), companies that recognize the value of flexibility in their investments are likely to have a significant competitive advantage.

Table 1 shows a list of studies containing real option's applications by area of application (Lander and Pinches, 1998; Drucker, 2002). The present study doesn't aim to be a survey of work in the field, and for that reason this brief overview of the literature is presented without further analysis. Our aim here is to emphasize that an increasing number of studies have incorporated the use of the real options methodology as an important valuation tool for different kinds of investment projects.

Table 1. Examples of real options applications classified by area

\begin{tabular}{|c|c|}
\hline Topic or Area & References \\
\hline \multirow{3}{*}{ Natural resources } & Tourinho (1979); Brennan and Schwartz \\
& (1985); Siegel, Smith and Paddock (1987, \\
& 1988); Trigerorgis (1990); Schwartz (1997, \\
& 1998); Smith (1997); Tufano (1998); \\
& Cortazar, Schwartz and Casassus (2000); \\
& Moel and Tufano (2000) \\
\hline \multirow{5}{*}{ Competition and corporate } & Baldwin (1982, 1989, 1991); Trigerorgis \\
& (1991, 1996); Kulatilaka and Perotti (1992); \\
strategies & Smith and Trigerorgis (1995); Grenadier \\
& and Weiss (1997); Farzin, Huisman, and \\
& Kort (1998); Busby and Pitts (1997); \\
& Economides (1999) \\
\hline \multirow{3}{*}{ Manufacturing } & Kulatilaka (1984, 1988, 1993); Baldwin and \\
& Clark (1994, 1996); He and Pindyck (1992); \\
& Kamrad and Ernst (1995); \\
& Mauer and Ott (1995) \\
\hline Housing and real estate & Stulz and Johnson (1985); Titman (1985); \\
& Capozza and Li (1994); Grenadier (1995, \\
& 1996); Childs, Riddiough, and Triantis \\
& (1996); Sirmans (1997); Downing and \\
& Wallace (2000) \\
\hline International & Baldwin (1987); Dixit (1989); Kogut and \\
& Kulatilaka (1994); Bell (1995); Buckley and \\
& Tse (1996); Capel (1997); Schich (1997); \\
& Buckley (1998) \\
\hline &
\end{tabular}


Table 1. Examples of real options applications classified by area (continue)

\begin{tabular}{|c|c|}
\hline Topic or Area & References \\
\hline R \& D & $\begin{array}{l}\text { Morris, Teisberg, and Kolbe (1991); } \\
\text { Newton and Pearson (1994); Childs, } \\
\text { Ottoo, and Triantis (1995); Falulkner } \\
\text { (1996); Ottoo and Thompson (1996); } \\
\text { Herath and Parkm (1999); Carter and } \\
\text { Edwards (2001); Perlitz, Peske, and } \\
\text { Schrank (2001) }\end{array}$ \\
\hline $\begin{array}{c}\text { Regulated firms and } \\
\text { utilities }\end{array}$ & $\begin{array}{c}\text { Mason and Baldwin (1988); } \\
\text { Teisberg (1990, 1993, 1994); } \\
\text { Edleson and Reinhardt (1995) } \\
\end{array}$ \\
\hline $\begin{array}{l}\text { M\&A and corporate } \\
\text { governance }\end{array}$ & $\begin{array}{c}\text { Hathaway (1990); Smith and Triantis } \\
(1994,1995) ; \text { Hiraki (1995); Vila and } \\
\text { Schary (1995); Ikenberry and } \\
\text { Vermaelen (1996) }\end{array}$ \\
\hline Interest rates & $\begin{array}{c}\text { Ingersoll and Ross (1992); Ross (1995); } \\
\text { Lee (1997) }\end{array}$ \\
\hline Inventory & $\begin{array}{c}\text { Chung (1990); Stowe and Gehr (1991); } \\
\text { Stowe and Su (1997) }\end{array}$ \\
\hline Labor force & Kandel and Pearson (1995); Bloom (2000) \\
\hline Venture capital & $\begin{array}{l}\text { Sahlman (1993); Willner (1995); } \\
\text { Gompers (1995); Zhang (1999) }\end{array}$ \\
\hline Advertising & $\begin{array}{l}\text { Epstein, Mayor, Schonbucher, } \\
\text { Whalley, and Wilmott (1998) }\end{array}$ \\
\hline Law & Triantis and Triantis (1998) \\
\hline $\begin{array}{c}\text { Hysteresis effects and firm } \\
\text { behavior }\end{array}$ & Pindyck (1991); Dixit and Pindyck (1994) \\
\hline $\begin{array}{l}\text { Environmental compliance } \\
\text { and conservation }\end{array}$ & $\begin{array}{c}\text { Purvis, Boggess, Moss, and Holt } \\
\text { (1995); Wiebe, Tegene, and Kuhn (1997) }\end{array}$ \\
\hline Industrial organization & Imai (2000); Huisman and Kort (2000) \\
\hline $\begin{array}{l}\text { Patents and innovation, high } \\
\text { technology pricing }\end{array}$ & $\begin{array}{c}\text { Schwartz and Moon (2000); Kellogg } \\
\text { and Charnes (2000); Bloom and Van } \\
\text { Reenen (2001); Boer (2000); } \\
\text { McGrath and MacMillan (2000) }\end{array}$ \\
\hline
\end{tabular}

Source Drucker, E. (2002).

Real Options Analysis also represents a tool capable of objectively measuring the intrinsic economic value of the flexibility of future choices in the context of M\&As valuations. For example, Smith and Triantis (1998) define three kinds of options that may be present in an acquisition; these options are: growth, flexibility, and divestiture potential. 
An acquisition represents, besides taking control of the target's market, the possibility to grow in neighboring markets. In that sense, the firm making the acquisition buys the rights to make further investments or acquisitions in geographically/activity related markets. At the same time, the acquirers may also create barriers to entry to rival firms, thus gaining an additional strategic advantage. The decision to go ahead with the necessary investments to grow the production capacity installed in order to serve an expanded market is, precisely, the exercise price of the option and, as such, it will only be undertaken if demand conditions are favorable.

By contrast, when the economy is not doing well and market perspectives are poor in the near future, the acquirer may consider either reducing the installed capacity in order to reduce fixed costs and to increase the utilized capacity ratio, or to liquidate its acquisition. When the option to liquidate or reduce the size of the acquired firm is incorporated in the analysis, the downside risk of the acquisition decision is minimized.

Brennan and Schwartz (1985) proposed a formal economic model to optimize the decision to either open or close a mine as mineral price change using real options theory. Moel and Tufano (2000) make an empirical study of mine closing in which they corroborate the theoretical predictions made by the theoretical model that appeared in Brennan and Schwartz (1985). The option to contract or liquidate an acquisition project may be analogous to the closing of a mine in the aforementioned studies.

Conventional acquisition analysis does not always account for the option to divest parts of the acquired companies at a later date. However, the future sale of those assets to other companies that would value them at a fair price may substantially limit downside risk. The divestiture option has been thoroughly analyzed in natural resources and mines valuation in several studies (Brennan and Schwartz, 1985), (Moel and Tufano, 2000), (Cortazar, Schwartz, and Casassus, 2000) but, to my knowledge, it has not been explicitly incorporated in M\&A valuation before.

Growth options often represent a significant value component in M\&As. However, the DCF approach frequently fails to value alternative courses of action that might result in further asset growth. Omitting ROA analysis of the potential asset growth opportunities implicit in an acquisition transaction could result in a decision of not to pursue an acquisition that would position the corporation in a key emerging market segment, and may have the effect of foreclosing important future value creating strategic options (Smith and Triantis, 1998).

\section{The Cement Industry: a clear pattern towards consolidation}

For some decades, the global cement industry has been characterized by an intense trend towards concentration. In that process several global firms compete face to face with local smaller firms and among themselves. One of the preferred growth strategies followed by major incumbents in the industry has been to grow by acquiring smaller firms. This consolidation pattern has not been limited to the domestic turf of the incumbent, but has clearly been projected into the international arena. While coment companies' acquisitions in more developed regions have represented the most significant number and the 
greatest value, targets in emerging markets have gradually increased in relative importance. In the absence of sufficiently developed capital markets where acquisitions of firms can take place through traditional tradable stock purchases in the open market, in most emerging market countries acquisitions take place through direct negotiations with either governments engaged in privatization processes or local owners. In those countries only in exceptional cases acquisitions of cement companies take place through hostile open market takeovers.

In general terms, it can be said that the value added by the acquiring firm is associated with organizational changes improving the efficiency of operations and the incorporation of more advanced production technologies, as well as potential complementarities when combining newly acquired plants with already existing facilities to serve an enlarged market.

The decision factor that influenced the choice of an acquisition in this industry to develop a ROA valuation was the large number of acquisitions that have taken place in it during the last decade. In most cases, global scale competitors have been the acquirers and targets have been smaller firms with only domestic activity. ${ }^{1}$

Besides, the particular enviromment in which many of the transactions of the major global players in the cement industry take place is especially adequate to apply the methodology, i.e. stable growth but significantly procyclical, potential intervention of emerging countries governments to regulate domestic markets (price, volume), technologically determined scale economies, a simple commodity only differentiated by the quality and variety of services attached to the product by the producer, etc.

It is very difficult to anticipate all possible strategic options that may arise in the acquisition process of a cement firm, so a choice was made to model three of the most common: the expansion option, the size reduction option and the sale or liquidation of the acquisition option.

As expressed above, managerial flexibility represents economic value in the sense that future increased profits opportunities will be taken and potential losses will be limited by timely decisions made by the management teain. The economic value represented by these three mutually exclusive alternatives is most often times disregarded when using a traditional DCF analysis or, alternatively, incorporated in a subjective manner. However, the ROA approach offers the possibility to frame the analysis in such a way that expected economic value can be objectively measure.

\section{Model Description}

The model developed values Cementia, the acquisition target of a multinational

1 The largest players in this market are: Holderbank, Lafarge and Cemex. These three companies have maintained an aggressive acquisition strategy during the last decade involving dozens of targets, many of them located in emerging economies all over the world. It is for that reason, that the cement industry represents an ideal environment to explore the use of ROA methodology to value acquisitions in environments that may be characterized as highly uncertain. 
company in the cement industry. ${ }^{2}$ Both, the target and the acquirer are located in two different emerging markets. While this fact might represent a problem for the determination of the adequate cost of opportunity of financial resources, the MNC's stock was traded in Wall Street, so its cost of capital could be estimated as any other public company traded in that market. ${ }^{3}$

As a first step, a traditional Discounted Cash Flow model was developed, based on reasonable projections. All the publicly available historical financial statements were used and, based on the historical sales, costs and assets produced ten years of free cash flow projections. In our projections we assumed a growth rate in sales of $4 \%$ during the first five years, and $5 \%$ for the following five years. In the tenth year we added a terminal value equivalent to the present value of a perpetuity that grows at a rate of $4 \%$. We also used a discount rate of $10 \%$ which was assumed to be the cost of opportunity that corresponds to the relevant risk of the target firm, i.e. the international CAPM estimated beta was used to determine the cost of capital. ${ }^{4}$

The discounted value of projected cash flows produced a "static" valuation of $\$ 42.34$ million USD (see Table 2). Considering that the firm had a balance of debt outstanding for $\$ 11.64$ million USD at the closing of the previous exercise, the resulting equity value was $\$ 30.70$ million USD (vs. $\$ 32.88$ million USD of accounting value).

Traditional DCF is usually adjusted upwards by top management to include potential synergies as well as other possible components that they foresee would increase the economic value of the target firm once it has been taken over. However, those adjustments are usually made in a subjective form, based on the experience and judgment of the executives involved in the process.

In what follows, this paper exemplifies the utilization of the ROA to determine the economic value implicit in future potential decisions that adopt the form of options (to expand, contract or liquidate) and that would be exercised under specific environmental conditions.

One of the basic insights that managers can obtain from the ROA is that the future is unpredictable, and our educated projections are only the most likely representation of the way the future may eventually look. However, the final outcome will depend on the trajectories of many different variables over which managers don't have any control.

However, managers do have control of the way they react in the face of environmental threats and opportunities and, for that reason, in order to reflect upon the potential responses that may be enforced as environmental conditions become more or less favorable, analysts must "model" the possible future scenarios before attempting valuing any strategic option.

2 For reasons of a confidentiality agreement signed with the acquiring firm, I am not allowed to reveal neither its name nor the target's.

3 Traditional Capital Asset Pricing Model utilization provided the cost of equity for the MNC.

4 The determination of the "correct" discount rate to value a firm in an emerging market is a subject open to debate. However, several authors have tackled with this issue in very creative ways. 
Uncertainty increases as projections are further away into the future, and that is the principle that gives support to the concept of the "cone of uncertainty", frequently used to describe the potential outcomes of an economic process.

There are multiple methodologies to solve an option's value, including closed-form equations like the Black and Scholes and its variations, Monte Carlo simulation methods, partial differential equations and binomial trees. ${ }^{5}$ In particular, binomial trees are easy to implement and highly flexible, but probably more important is the fact that in the limit, as time is "sliced" ever more thinly, results obtained through the use of binomial trees approach those derived from closed-form solutions.

While closed solutions are more elegant and efficient, it is not always possible to come out with a feasible solution to specific forms or combinations of real options. Hence, binomial trees are not only frequently much more amenable to work-out these problems, but also highly flexible to incorporate the specificities of as many future decisions as desired. In what follows, this exercise adopts the binomial tree approach combined with Monte Carlo simulation to model and value the strategic options available to the acquiring firm.

\section{The Estimation of Intrinsic Volatility of the Target Firm}

The binomial tree methodology to value a financial option ${ }^{6}$ assumes that the value of the asset underlying the contract fluctuates through time according to some parameter called its "intrinsic volatility". While attempting to predict the future path of a financial asset's value would represent a contradiction of the Efficient Markets Hypothesis, making the assumption that the underlying asset will exhibit a certain volatility pattern, generally estimated through a time series analysis of its past prices, is acceptable. It just assumes that the historical volatility patterns which characterized the asset, will continue into the future.

Adapting the binomial tree analysis to determine the Expanded Economic Value (DCF + Real Options) of a target firm in a M\&A process implies the identification of the value of the firm as the underlying asset that must be modeled in order to determine the value of future strategic choices, i.e. the implicit real options to the acquiring firm.

While the stock price of the target firm in the capital markets reflects the true value of the firm and could in principle be used to measure the intrinsic volatility needed to build the binomial tree of the underlying asset, the validity of measure is subject to the informational efficiency of the market in which the stock is traded.

However, it is very often the case that in emerging economies' capital markets the frequency of trading of stocks is very low and, for that reason. the observed stock price volatility is severely biased by thin trading. In other even more frequent cases, the stock of the target firm is simply not publicly traded.

5 Trinomial, quadrinomial, and multinomial trees can also be constructed for specific purposes.

6 See, for example, Hull (2002), chapter 10. 
In the design of our model the evidence of a very thinly traded stock suggested the utilization of an alternative methodology to measure the intrinsic volatility of the target firm.

There are different ways to estimate a set of future cash flows volatility, i.e. the Logarithmic Cash-Flow Returns Approach, the Management Subjective Approach and the Logarithmic Present-Value Approach (Mun, 2002). To estimate the intrinsic volatility of the target firm we recurred to the Logarithmic Present-Value Approach which is based on a Monte Carlo simulation, ${ }^{7}$ generating thousands of possible random values for a number of influential input variables introduced in the DCF model with specific statistical distributions.

The type of statistical distribution assigned to each driver variable was established by performing a time series analysis of historical observations; however, when no previous history exists, subjective judgment of technical personnel might fill the void.

The simulated variables include the annual inflation rates in Latinlandia and the United States, the interest rate that applies to Cementia, the sales growth and cost figures, assuming normal distribution for these inputs, the proportion of fixed assets to total sales, and the proportion of current liabilities as a proportion of total assets. Another indirectly simulated variable was the exchange rate of Latinlandia's pesos vs. the US Dollar, based on the purchasing power parity model.

The variable of interest to measure intrinsic volatility was defined as the standard deviation of the rate of return between discounted cash flows to time zero and again to time 1 . The present values of individual annual cash flows are summed and the following logarithmic ratio is calculated:

$$
X=\ln \left[\frac{\sum_{i=1}^{n} P V C F_{i, 1}}{\sum_{i=1}^{n} P V C F_{i, 0}}\right]
$$

$P V C F_{i, t}$ represents the present value of future cash flows generated at different time periods $i$, discounted to period $t$, i.e., the numerator is equal to the sum of discounted cash flows to time 1 and the denominator is the sum of discounted cash flows to time 0 .

The model pretends to represent the rate of return of the underlying asset (the present value of the investment) between periods 0 and 1 , and through simulation to infer the standard deviation of the rate of return between year 0 and year 1 .

The $X$ is defined as the output of the simulation exercise and the distribution generated by several thousand combinations of possible values of the driver variables will correspond to the distribution of the possible future returns. Finally, the standard deviation of the $X$ variable which represented the estimated intrinsic volatility of the underlying asset was found to be $29 \%{ }^{8}$

7 This approach was introduced by Copeland and Antikarov (2001) and is also cited in Mun (2002).

8 Copeland and Antikarov (2001) present a detailed analysis of volatily estimation of an investment project. 


\section{The Construction of the Underlying Asset and the Option Valua- tion Binomial Trees}

With the projected cash flows and the intrinsic volatily measure obtained from simulation we proceeded to construct a value-based event tree, which provides the values of the underlying project without flexibility.

As described above, binomial trees can be adapted to incorporate both the expected behavior of the underlying asset value and the potential value of the decisions managers would make by optimally choosing what to do under different environmental circumstances. To achieve that goal, the next step consisted in placing "if" decisions that maximize the value of the "flexible" underlying asset into each one of the nodes of the tree, thus turning it into a decision tree. The last step of this stage consisted in using the risk-neutral probability approach to value the optimal decisions embedded in the decision tree to obtain the value of the target firm with flexibility.

The approach used to determine the value of several combined future options is called the "backwards-induction" " which basically determines what is the best solution in each terminal node of the binomial tree and then moves backwards (hence the name) to determine if one period before the optimal decision was to exercise any of the available options or to leave the underlying asset unaffected since keeping the options open represents greater economic value.

Basically, the model builds a conventional binomial tree for the value of the underlying asset (in this case the value of the equity obtained from the DCF analysis) by incorporating the intrinsic volatility of the asset (previously obtained from the DCF model through a Monte Carlo simulation). Then evaluates what is the maximal value at each node between the different possibilities, including doing nothing at that particular node, and finally discounts the riskneutral probability weighted values of each node back to the initial node. We used a $5 \%$ risk free rate and a ten year horizon assuming decision moments at six month intervals. While this was an oversimplification of the kind of real options problems present in the real world of acquisitions, we expect it will serve the objective of serving to exemplify the application of ROA as a complement of DCF to value acquisitions.

The hypothetical options we modeled and valued were the following:

- First Option was: the expansion by a factor of 2 times, with an additional investment of $\$ 20$ million USD.

- Second Option was: the contraction of the size of the plant, assuming a marginal reduction of productive capacity (closure of plants, sale of old machinery, reduction of the work force) in the order of $10 \%$ that would result in a fixed costs reduction of $\$ 5$ million USD.

- Third Option was: liquidation of the target firm, interpreted as the possibility to make the decision to sell it if the environmental conditions become unfavorable, for a price equivalent to $\$ 20$ million USD. While this assumption would formally require a compromise of another party to pay that price, we believe that given the characteristics of the firm and the conditions of the market for cement companies this is not an unrealistic price.

9 See Hull (2002), chapter 10 . 


\section{The ROA Results and Interpretation}

The input area of the ROA spreadsheet is presented as Table 2. It basically includes all the parameters described above.

Table 2

\begin{tabular}{|c|c|}
\hline Expiration in Years & 10 \\
\hline Volatility & $29.00 \%$ \\
\hline PV Asset & $\$ 42.34$ \\
\hline Risk-Free Rate & $5.00 \%$ \\
\hline Dividend Rate & $0.00 \%$ \\
\hline Expansion Factor & 2.00 \\
\hline Expansion Cost & $\$ 20.00$ \\
\hline Contraction Factor & 0.90 \\
\hline Contraction Savings & $\$ 5.00$ \\
\hline Salvage Value & $\$ 20.00$ \\
\hline
\end{tabular}

The underlying asset value binomial tree construction for five periods, based on the intrinsic volatility obtained from the Monte Carlo simulation, as well as the valuation binomial tree developed through backwards induction and riskneutral valuation are reported in Table 3 .

Table 3

\begin{tabular}{rrrrrr}
\hline Step 0 & Step 1 & Step 2 & Step 3 & Step 4 & Step 5 \\
\hline 42.34 & 63.81 & 96.16 & 144.91 & 218.38 & 329.09 \\
& 28.10 & 42.34 & 63.81 & 96.16 & 144.91 \\
& & 18.64 & 28.10 & 42.34 & 63.81 \\
& & & 12.37 & 18.64 & 28.10 \\
& & & & 8.21 & 12.37 \\
74.30 & & & & & 5.45 \\
& 114.73 & 177.50 & 273.44 & 418.66 & 638.19 \\
& 46.26 & 71.09 & 111.24 & 174.22 & 269.82 \\
& & 29.19 & 42.65 & 66.58 & 107.61 \\
& & & 20.83 & 25.77 & 36.19 \\
& & & & 20.00 & 20.00 \\
& & & & & 20.00 \\
\hline
\end{tabular}

The $\$ 74.30$ million USD represents the value of the acquisition including the flexibility implicit in the possibility of choice among the three alternative strategic options, depending on the "state of nature" modeled by the Underlying Asset Pricing Lattice.

This valuation is significantly greater $(75 \%)$ than the value obtained through DCF. Our results can give a good idea of the potential value that is sometimes not formally incorporated in acquisition valuation processes. 
The difference between the value of the acquisition when valued with flexibility (Real Options Approach) and the value obtained through DCF is equal to the value of the Real Options implicit in the acquisition, i.e., $\$ 31.96$ million USD, and it represents a margin for negotiation with current owners, from the perspective of the acquirer.

With a more precise estimation of the economic value contained in the target firm, the acquiring firm can develop a soundly based negotiating strategy within a given range of values, providing negotiators with "hard" parameters in the definition of the final bid.

The "optimal decisions" tree, corresponding to the values of the option valuation lattice above, and showing what is the best choice between the three possible: expansion, contraction or liquidation (or, alternatively, the fourth choice of not doing anything) at each node is reported in Table 4.

Table 4

\begin{tabular}{llllll}
\hline continue & continue & continue & continue & continue & Expand \\
& continue & continue & continue & continue & Expand \\
& & continue & continue & continue & Expand \\
& & continue & continue & Expand \\
& & & Abandon & Abandon \\
& & & & Abandon \\
\hline
\end{tabular}

The expansion option (Expand) would be exercised when the underlying asset's value justifies the investment of $\$ 20$ million USD, in new plant and equipment. The liquidation option, by contrast is chosen when the value of the underlying is lowest. The contract option is never optimal (at this level of desegregation).

Graphically, the value profile of this combination of options shows that the existence of both liquidation and expansion options would create additional value for the acquirer under extreme movements of the underlying asset's value, since they represent real options whose value increases as the underlying either builds up (expansion) or diminishes (liquidation). This combination of real options closely resembles the profile of a "Butterfly Strategy", common to financial options traders, where the combination of a call and a put option provide a significant profit potential if the underlying asset price moves up or down by a significant amount, as shown in Figure 2.

As a last step to our Real Options Analysis we combined the binomial tree RO valuation model with a Monte Carlo Simulation of the DCF valuation to get a better grasp of the probabilistic dispersion of the Expanded Economic Value (EEV) of the target firm.

By generating a new distribution of values for the input variables, the model creates a distribution of underlying asset values that are, in turn, converted into a distribution of $\mathrm{EEV}$, which is presented as Figure 3 for 1000 iterations.

The usefulness of this step is that is provides a visual representation of the probabilistic values of the acquisition firm, from the perspective of the candidate acquirer, but also allows the determination of a cumulative relative frequency of outcomes for established thresholds. 
Figure 2

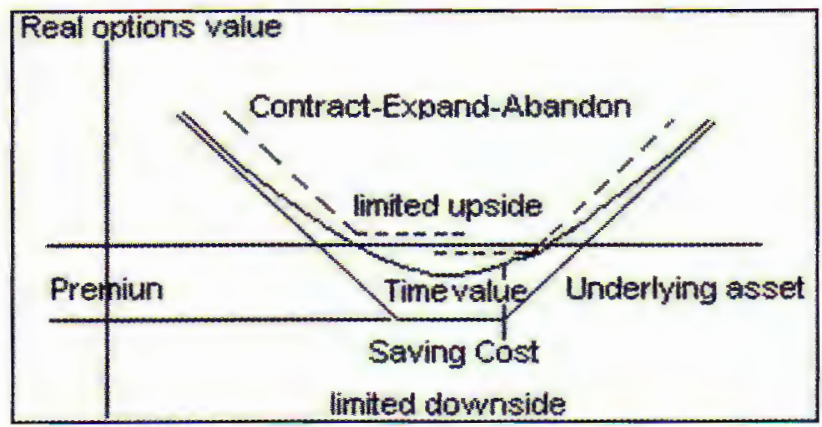

Figure 3. Forecast: expanded economic value of the potential Frequency chart

\section{CYystal Bar Acadenic Eodition \\ Not for Comnercial Lse \\ 1,000 Trials}

996 cisplayed

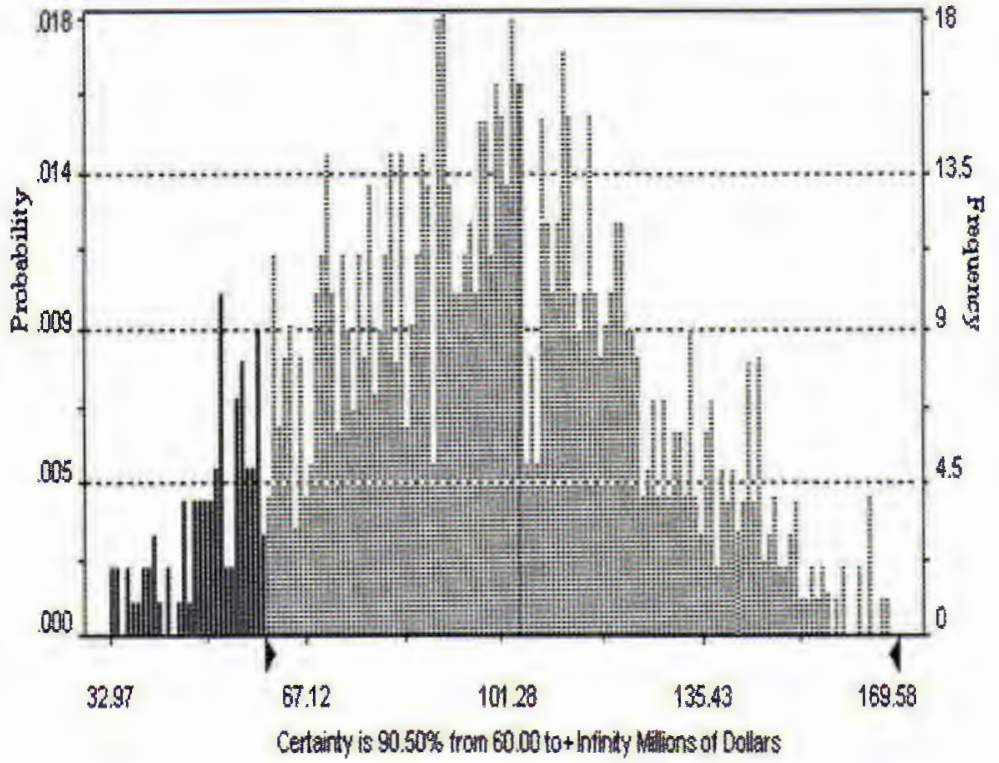

For example, as represented in Figure 3, the cumulative relative frequency of outcomes whose value is below 50 million dollars is equal to $9.5 \%$, a reasonable level of risk by most standards. Thus, the bidding firm can confidently make an acquisition bid of up to that amount with the confidence that it is undertaking a relatively safe bet.

That level of certainty can be modified to create different scenarios that are very helpful to present the plan to top management, the board of directors or other managers involved in the acquisition decision process. 


\section{Conclusion}

As a result of the particular characteristics of evolving technologies, markets dynamics and the life cycle stage in which they are, certain industries report a larger number of annual acquisition transactions. The cement industry is one such industry in which major global players are increasing the concentration of ownership of cement plants all over the planet through aggressive strategies of acquisition of smaller players. The privatization process that has encompassed most countries during the last decades has been an active ingredient in that process.

Numerous studies report that acquisitions often have unexpected consequences for the acquiring firm because the price paid for the target exceeds its true economic value. After a review of the acquisitions literature one can find abundant evidence of valuation inconsistencies.

The Real Options Analysis Methodology contributes to this debate by providing a sound theoretical approach to value acquisitions with increased precision, as the traditional DCF is not capable of incorporating the economic value of flexibility to undertake the necessary measures to profit from windfall markets or to reduce losses by contracting operations or even liquidating the investment.

In this paper we discussed the valuation of a cement company acquisition located in an emerging country, a frequent event in that industry, using a combination of DCF and ROA.

After the analysis we discovered that three Real Options ex-post explicitly identified by the acquiring firm management team as embedded in the target, were more valuable than the original value attributed to the DCF. As a result, we obtained an objective estimation of a reasonable ceiling for the price paid in the acquisition negotiation process.

While the number of real options in an acquisition may be much larger, this hypothetical example illustrate what are the potential benefits of identifying the most important in terms of their proportional contribution to the value of the target. With this, senior executives will be better informed about the objective limits of price negotiations.

\section{References}

Baldwin, R. (1987). Politically realistic objective functions and trade policy profs and tariffs. Economics Letters, 24(3), pp. 287-290.

Brennan, M. and E. Schwartz (1985). Evaluating Natural Resource Investments. The Journal of Business, 58(2), pp. 135-157

Chavez, C. (1998). Valuación de proyectos utilizando la técnica de opciones reales y su aplicación en un caso específico: flexibilidad de manufactura. Mimeo.

Cortazar, G., E. Schwartz, and J. Casassus (2000). Optimal Exploration Investments under Price and Geological Technical Uncertainty: a Real Options Model. EFMA. Athens.

Copeland, T. and V. Antikarov (2001). Real Options: a Practitioner's Guide. W.W. Norton \& Company.

Downing, C. and N. Wallace (2000). A Real Options Approach to Housing Investment. FEDS. Working Paper 2000-30.

Drucker, E. (2002). Towards The Development of a New Methodology for the Evaluation of Strategic Acquisition Projects with the use of Real Options. Mimeo. EGADE. I.T.E.S.M. 
Eccles, R., K. Lanes, and T. Wilson (1999). Are You Paying too much for that Acquisition?. Harvard Business Review. July-August.

Economides, N. (1999). Real Options and the Costs of the Local Telecommunications Network. New York University. Working Paper 99-1007.

Herath, H. and C. Park (2001). Real Options Valuation and its Relationship to Bayesian decision making Methods. The Engineering Economist, 46(1), pp. 1-32.

Huisman, K. and P. Kort (2000). Strategic Technology adoption Taking into Account Future Technological Improvements: a Real Options Approach. Tilburg University. Center for Economic Research. Working Paper no. 52.

Hull, J. (2002). Options, futures and other derivatives. Upper Saddle River, NJ: Prentice Hall.

Ikenberry, D., J. Lakonishok, and T. Vermaelen (1999). Stock Repurchases in Canada: performance and strategic trading. NBER. Working Paper 7325.

Ingersoll, J. and S. Ross (1992). Waiting to invest: Investment and Uncertainty, Journal of Business, 65(1), pp. 1-29.

Kogut, B. and N. Kulatilaka (2001). Strategy, Heuristics, and Real Options. The Oxford Handbook of Strategy.

Kulatilaka, N. and E. Perotti (1998). Strategic Growth Options. Management Science, 44(8), pp. 1021-1031.

Kulatilaka, N. and L. Trigerorgis (1994). The General Flexibility to Switch: Real Options Revisited. International Journal of Finance, 6(2), pp. 27-54.

Lander, D. and G. Pinches (1998). Challenges to the Practical Implementation of Modeling and Valuing Real Options. The Quarterly Review of Economics and Finance, 38, pp. 537-567.

McGrath, R. and I. MacMillan (2000). Assessing Technology Projects using Real Options Reasoning. Research Technology Management, 43(4), pp. 35-49.

Moel, A. and P. Tufano (2000). When are Real Options Exercised? An Empirical Study of Mine Closings. Harvard Business School. Working Paper 99-117.

Mun, J. (2002). Real Options Analysis, Wiley.

Mun, J. (2003). Real Options Analysis Course, Wiley.

Nielsen, J. and R. Melicher (1973). A Financial Analysis of Acquisition and Merger Premiums. The Journal of Financial and Quantitative Analysis, 8(2), pp. 139-148.

Ottoo, R. (2000). Valuation of Corporate Growth Opportunities: a Real Options Approach. Garland Publishing: New York.

Schwartz, E. and C. Zozaya-Gorostiza (2000). Valuation of Information Technology Investments as Real Options. AFA. New Orleans Meetings.

Schwartz, E. and M. Moon (2000). Rational Pricing of Internet Companies. Financial Analysis Journal, 56(3), pp. 1-31. 